\title{
Design approach for optimization of a piston ring profile considering mixed lubrication
}

\author{
Zhinan ZHANG ${ }^{1,2, *}$, Jun LIU', Youbai XIE ${ }^{1,2}$ \\ ${ }^{1}$ State Key Laboratory of Mechanical System and Vibration, Shanghai Jiao Tong University, Shanghai 200240, China \\ ${ }^{2}$ School of Mechanical Engineering, Shanghai Jiao Tong University, Shanghai 200240, China \\ Received: 19 September 2016 / Revised: 02 November 2016 / Accepted: 08 November 2016 \\ (C) The author(s) 2016. This article is published with open access at Springerlink.com
}

\begin{abstract}
To reduce the friction of a piston ring while maintaining a large oil film load-carrying capacity, an approach comprising of the inverse method and the sequential quadratic programming algorithm was proposed. The approach considers the variation of mixed lubrication and variable lubricant viscosity with temperature along the engine stroke, is developed to optimize the profile of a piston ring. A piston ring profile is represented by a polynomial function. A case study of the second piston ring shows that the proposed method can be applied for the optimization of a piston ring profile. In addition, this paper illustrates the effects of the degree of a polynomial function. The results show that the minimization of friction and maximization of oil film load-carrying capacity can be balanced simultaneously when the degree of the polynomial is 2 and 5 .
\end{abstract}

Keywords: piston ring profile; inverse method; tribology design; mixed lubrication; hydrodynamic lubrication

\section{Introduction}

In recent years, there is an increasing demand for technologies that reduce fuel consumption. The piston ring and cylinder liner are the core components of engine tribosystems. The tribological behavior of these tribosystems has a substantial influence on engine friction power loss, fuel consumption, harmful emissions, and effective gas sealing. It has been estimated that about 20 to 30 percent of an engine's mechanical power loss is caused by the friction loss in the ring/liner tribosystem [1,2]. A good lubrication state in the ring/liner interface is vital for reducing engine friction and improving engine performance [3,4]. Improving the lubrication condition for the reduction in engine friction loss, while maintaining the primary function of piston ring, are long-term goals that researchers have been pursuing [3-8]. A better designed piston ring profile is able to generate a better lubrication state [9]. Therefore, effort is required to develop a

* Corresponding author: Zhinan ZHANG.

E-mail: zhinanz@sjtu.edu.cn method to optimize the profile of the piston ring face, such that it has a better lubrication state for the reduction in friction, while also maintaining the primary function of piston ring.

\section{Related work}

A considerable number of studies have been devoted to improving the tribological performance of the ring/ liner tribosystem [2-9]. Numerous methods have been developed to reduce friction power loss in the piston ring pack and improve fuel economy. Among these methods, many factors affecting ring friction have been taken into account. These methods can be divided into three primary categories: (1) lubrication state improvement, (2) surface modification, and (3) design parameter optimization.

\subsection{Methods for lubrication improvement}

Efforts have been made to analyze the lubrication state at the ring/liner interface. For example, Furuhama [4] calculated the thickness of the lubricant film by 


\begin{tabular}{|llll}
\multicolumn{2}{l}{ Nomenclature } & & \\
$\kappa, \theta_{1}, \theta_{2}$ & Parameters in the Vogel equation & $\eta_{\mathrm{p}}$ & Density of asperity \\
$h_{0}$ & Outlet film thickness & $\tau_{0}$ & Constant of shear stress \\
$h_{\mathrm{m}}$ & Minimum film thickness & $\phi_{\mathrm{c}}$ & Contact factor \\
$h_{\mathrm{s}}$ & Shoulder length & $\phi_{\mathrm{fg}}$ & Geometric stress factor \\
$A_{\mathrm{c}}$ & Actual contact area & $\phi_{\mathrm{fp}}$ & Pressure stress factor \\
$F_{2.5}$ & Intermediate variable & $\phi_{\mathrm{fs}}$ & Shear stress factors \\
$F_{\mathrm{a}}$ & Asperity contact friction force & $\phi_{\mathrm{s}}$ & Shear flow factor \\
$F_{\mathrm{e}}$ & Piston ring elastic force & $\phi_{\mathrm{x}}$ & Pressure flow factors \\
$F_{\mathrm{g}}$ & Gas force at inner side of piston ring & $A$ & Area of nominal contact \\
$F_{\mathrm{oil}}$ & Load-carrying capacity of film & $b$ & Piston ring width \\
$F_{\mathrm{t}}$ & Total friction force & $h$ & Film thickness \\
$F_{\mathrm{V}}$ & The viscous shearing force of film & $r$ & Crank speed \\
$P_{1}$ & Pressure on the ring & $\eta$ & Lubricant viscosity \\
$P_{2}$ & Pressure below the ring & $\sigma$ & Composite roughness \\
$T_{\mathrm{BDC}}$ & The liner temperature at the bottom & $E$ & Composite elastic modulus of the materials' \\
& dead center (BDC) & & contact surface \\
$T_{\mathrm{MID}}$ & The liner temperature at the mid-stroke & $S$ & The length of the piston stroke \\
& point (MID) & $l$ & Connecting rod length \\
$T_{\mathrm{TDC}}$ & The liner temperature at the top dead & $p$ & Oil film pressure \\
& center (TDC) & $t$ & Time \\
$V_{\mathrm{p}}$ & Piston velocity & $x$ & The piston location downward from TDC \\
$W_{\mathrm{a}}$ & Asperity contact force & $\beta$ & Fixed asperity radius of curvature \\
$p_{0}$ & Normal gas pressure & & Crank angle \\
$\alpha_{0}$ & Boundary friction coefficient & & Angular speed of crankshaft \\
$\eta_{0}$ & Viscosity invariant & & \\
& & &
\end{tabular}

considering the squeeze film effect. Dowson et al. [5] used a hydrodynamic lubrication model with a Reynolds boundary condition and considered the effect of oil starvation to study piston ring lubrication. To predict the tribological performance of the piston and cylinder liner more accurately, some researchers $[8,10]$ used Patir and Cheng's Averaged Reynolds equation [11] and Greenwood-Tripps's asperity contact model [12] to simulate mixed lubrication. Akalin and Newaz $[8,13]$ presented both simulations and experimental studies in their investigation on mixed lubrication of a piston ring. Their results showed a strong agreement between the simulation and measured friction. Styles et al. [14] developed a numerical model for the analysis of a mixed lubrication regime at the top compression ring. Their model was also based on the GreenwoodTripp model and Reynolds equation. Recently, Guo et al. [15] developed a mixed lubrication model for piston ring pack analysis. The elastoplastic contact of the ring/liner was considered in their model. The focus of the aforementioned contributions was on achieving a more precise analysis of ring/liner lubrication behavior.

\subsection{Surface modification}

The modification of a piston ring surface has recently become a popular research topic. Both the surface coating and surface texturing have received sufficient attention. For example, Tung and Gao [16] presented a case study on investigating the tribological characteristics of piston ring coatings. The coatings included thermally-sprayed $\mathrm{CrN}$ and physical vapor deposited diamond-like-carbon (DLC). Their study showed that the DLC coating can effectively reduce ring wear. 
Kano [17] presented an overview of DLC-coated engine components. Currently, DLC coating is being successfully applied to piston rings. Skopp et al. [18] applied thermally sprayed titanium suboxide coatings to the piston ring and liner. The performance of this coating was tested under mixed lubrication and dry-running conditions. For the latter, the pioneering work by Etsion and Sher [19] showed that surface texturing technology can be efficiently used to reduce friction loss in the ring/liner tribosystem. Zavos and Nikolakopoulos [20] presented a computational study regarding the effect of surface texturing on the tribological behavior of the piston ring. Tomanik et al. [21], Biboutlet et al. [22], and Urabe et al. [23] studied the effects of various surface textures on the reduction in piston ring friction. It can be concluded that the efficiency of surface texturing on engine friction reduction has been recognized by a number of studies.

\subsection{Design parameter optimization}

Numerous studies have also been devoted to optimizing the piston ring and cylinder liner systems by taking piston ring design parameters into account. For example, Tian [7, 24] comprehensively studied piston ring design parameters such as ring width, materials, ring twist, torsional stiffness, and ring-groove clearance to analyze the dynamic behavior of piston rings and their impact on gas flow and oil transport. Kapsiz et al. [25] used the Taguchi design method to optimize the friction and wear between the piston ring and cylinder liner pair. The focuses of their experimental study were on the sliding velocity, applied load, oil type, and the material of the ring and liner. Researcher also adopted a design of experiments (DoE) method [26] to optimize a piston ring group. Their results showed that using this method can significantly reduce friction power loss. Morris et al. [27] and Wu et al. [28] carried out a simulation study on the influence of piston ring geometry and topography on piston ring and cylinder liner friction. Singh et al. [29] used an experimental study to investigate the effect of modified profiles of the piston ring face on the performance of a diesel engine. Cheng and Chang [30] applied the inverse method to design the shape of a slider surface to meet the requirements of special pressure distribution, resultant forces, and centers of load. More recently, the inverse method was applied to the design of a piston ring profile by $\mathrm{Chu}$ et al. [9] and the optimum design of slider bearings by $\mathrm{Chu}$ [31]. In their study, the Gauss-Seidel method and the Newton-Raphson method were employed with the inverse algorithm for estimating the piston ring profile and pressure distribution. However, there is still a dearth in efficient methods to optimize the profile of the piston ring, considering all the inherent complexities of the interface associated with mixed lubrication effects and variable lubricant viscosity.

Although researchers have studied the effects of profiles of the piston ring face on engine performance and investigated how to use an inverse method to optimize the piston ring face, their focus was on the relationship between the ring shape and pressure distribution, while only considering hydrodynamic lubrication. In addition, some factors were neglected in their study; these include the variation of lubricant viscosity with temperature along the engine stroke, gas pressure and engine speed, and mixed lubrication regimes. However, the key areas where friction is an issue are at reversal points, most noticeably before the power stroke. The combination of high pressure with high temperature results in small film thicknesses and increases the likelihood of a mixed lubrication regime. Therefore, it would be beneficial to examine lubrication regimes as well as hydrodynamics, when discussing friction reduction.

As mentioned previously, insufficient attention has been paid to the effect of the profiles of the piston ring face on engine performance, while improving the overall tribological performance of piston ring-cylinder liner contacts. This study aims to develop a profile design for the optimization of a piston ring face in mixed lubrication. Chu et al. [9] and Elsharkawy and Alyaqout [32] used the inverse method to optimize the shape of the piston ring face and porous slider bearing. In the inverse method, the boundary conditions are unknown and can be represented in a form of a polynomial function with an undetermined coefficient. By using the least-square error method, the system equations can be constructed to solve the undetermined coefficient [31]. As has been stated and verified by Elsharkawy and Alyaqout [32], the optimization process of the sequential quadratic programming (SQP) 
algorithm is not only easy to fulfill; however, it has a better convergence than Chu's algorithm [31]. The primary purpose of the SQP algorithm is to solve one or more quadratic programming sub-problems around an approximate solution and then seek a better approximate solution based on those solutions. In this paper, initial values were assumed for the coefficients, and then the SQP algorithm was used to update the values of the coefficients based on the objective function and the constraints, until the termination criteria were achieved [32]. Therefore, this study applied the reverse method and SQP algorithm to optimize the shape of the piston ring face. In contrast to existing work $[9,30-32]$, the effects of varied piston velocity and gas pressure, mixed lubrication, and the characteristics of the lubricant on the optimization, were taken into account. Based on the proposed approach, the effect of the shapes of piston ring faces on the friction and oil film load- carrying capacity was studied.

\section{Model development}

\subsection{Governing equation}

The schematic of the piston ring and cylinder liner system is shown in Fig. 1 (see the nomenclature). This includes all necessary geometric parameters, forces, and pressures that are required to derive the equations for analyzing the dynamic and tribological behavior of a piston ring. As shown in Fig. 1, $l$ is the length of connecting rod, $r$ is the crank radius, $b$ is the ring width, $\omega$ is the crank speed, $P_{1}$ is the gas pressure acting on the upside of a ring, $P_{2}$ is the gas pressure acting on the below side of a ring, $F_{\mathrm{g}}$ is gas force on the inner side of a ring, $P_{\mathrm{e}}$ is the ring elastic force, $F_{\mathrm{oil}}$ is the oil film load-carrying capacity, $W_{\mathrm{a}}$ is the asperity contact force, $h$ is the oil film thickness, $h_{\mathrm{m}}$ is the minimum oil film thickness, $h_{0}$ is the outlet oil film thickness, $h_{\mathrm{s}}$ is the shoulder length, and $V_{\mathrm{p}}$ is the reciprocating velocity of the piston.

During the engine cycle, the axial piston velocity varies with the crank angle, with the velocity temporarily reaching zero at reversal points. For a constant crank speed $\omega$, the piston position $x$ and velocity $V_{\mathrm{p}}$ along the axis of the cylinder can be determined respectively using the following equations:

$$
\begin{gathered}
x=r(1-\cos \theta)+l-\sqrt{l^{2}-r^{2} \sin ^{2} \theta} \\
V_{\mathrm{p}}=\dot{x}=r \omega\left(\sin \theta+\frac{r \sin 2 \theta}{2 \sqrt{l^{2}-r^{2} \sin ^{2} \theta}}\right)
\end{gathered}
$$

The following assumptions were made to reduce the complexity in using the inverse method: (a) the piston ring was circumferentially symmetric, (b) ring deformation and tilt did not occur, and (c) surface deformation (EHL effect) was not considered in the simulation, i.e., the contact surfaces were assumed to be rigid.

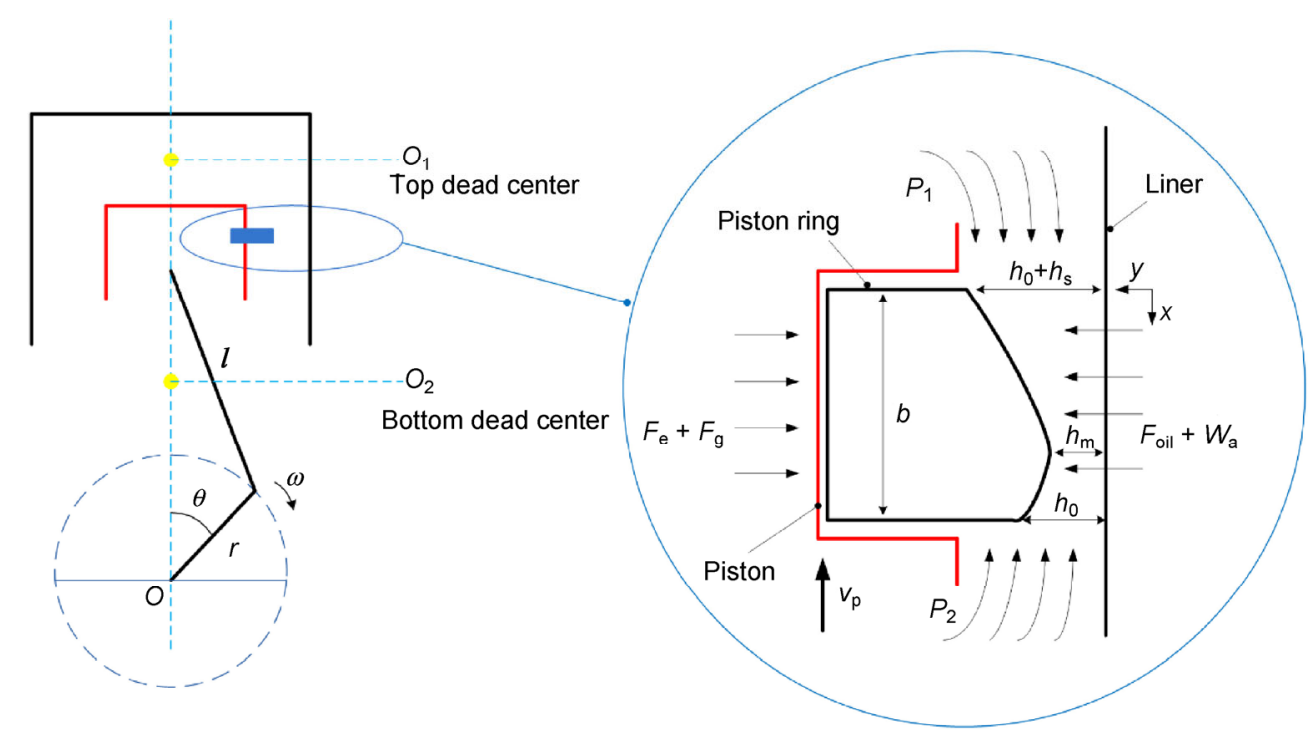

Fig. 1 Schematic drawing of a piston ring and cylinder liner system. 
With reference to the above assumptions, the development of a geometric optimization approach was the primary concern of this study. To simplify the study to a one-dimensional problem, assuming a perfectly circular cylinder liner and axisymmetric ringliner contact, and neglecting the effect of change in the film thickness in the circumferential direction, the one-dimensional version of Patir and Cheng's flow factor model with the classic Reynolds cavitation condition in consideration was adopted:

$$
\frac{\partial}{\partial x}\left(\phi_{x} \frac{h^{3}}{\eta} \frac{\partial P}{\partial x}\right)=6 \phi_{\mathrm{c}} V_{\mathrm{p}} \frac{\partial h}{\partial x}+6 V_{\mathrm{p}} \sigma \frac{\partial \phi_{\mathrm{s}}}{\partial x}+12 \phi_{\mathrm{c}} \frac{\partial h}{\partial t}
$$

where $\phi_{x}$ is the pressure flow factor, $\phi_{\mathrm{c}}$ is the contact pressure factor, $\phi_{\mathrm{s}}$ is the shear flow factor, $\sigma$ is the composite roughness, $\eta$ is the viscosity of lubricant, $h$ is the oil film thickness, and $\sigma=\sqrt{\sigma_{1}^{2}+\sigma_{2}^{2}} / 2$ is the composite roughness. Detailed information about these factors can be found in the published work by Patir and Cheng [11] and Meng et al. [33].

The following non-dimensional variables were selected:

$$
X=\frac{x}{b}, P=\frac{p}{p_{0}}, H=\frac{h}{\sigma}, U=\frac{V_{\mathrm{p}}}{\omega r}, \theta=\omega t, \bar{\eta}=\frac{\eta}{\eta_{0}}
$$

where, $P_{0}$ is $0.1 \mathrm{MPa}$, and $\eta_{0}$ is $0.0097 \mathrm{~Pa} \cdot \mathrm{s}$. As illustrated in Fig. 1, the modified Reynolds cavitation boundary conditions for Eq. (3) are [11]:

$$
\begin{gathered}
\mathrm{P}=P_{1}, \text { at } X=X_{\mathrm{i}}, \\
\mathrm{P}=P_{2} \text { and } \frac{\mathrm{d} P}{\mathrm{~d} X}=0, \text { at } X=X_{\mathrm{c}},
\end{gathered}
$$

where $X_{\mathrm{i}}$ is the axial coordinate at the inlet, and $X_{\mathrm{c}}$ is the axial coordinate at the cavitation boundary. When the piston moves downward, the position of $X_{i}$ is at the bottom edge of the ring, and the position of $X_{c}$ is at the cavitation boundary, which is at the upper portion of the ring. When the piston moves upward, the position of $X_{\mathrm{i}}$ is at the top edge of ring, and the position of $X_{c}$ is at the cavitation boundary, which is at the lower portion of the ring. Because the positions of $X_{\mathrm{i}}$ and $X_{\mathrm{c}}$ change, they are not marked in Fig. 1 .

The dimensionless form of the load-carrying capacity of the oil film can be written as follows:

$$
F_{\text {oil }}=\int_{0}^{1} P \mathrm{~d} X
$$

When the value of the film thickness ratio, $H=\frac{h}{\sigma}$, is below 4.0, the asperity contact is considered. The contact force $W_{\mathrm{a}}$ can be calculated by the GreenwoodTripp's asperity contact model [12] as follows:

$$
W_{\mathrm{a}}=\frac{16 \sqrt{2}}{15} \pi\left(\eta_{\mathrm{p}} \beta \sigma\right)^{2} E \sqrt{\frac{\sigma}{\beta}} A F_{2.5}\left(\frac{h}{\sigma}\right)
$$

where $\eta_{0}$ is the density of asperity, $\beta$ is fixed asperity radius of curvature, $E$ is the composite elastic modulus of the material's contact surface, $A$ is the area of nominal contact, and $F_{2.5}$ is an intermediate variable.

After neglecting the dynamics of the piston ring (e.g., the ring's relative motion inside the piston groove), the equilibrium of forces acting on the piston ring can be written as:

$$
F_{\mathrm{g}}+F_{\mathrm{e}}=F_{\text {oil }}+W_{\mathrm{a}}
$$

The friction force caused by the viscous shearing force of the oil film can be computed by [34]:

$$
F_{\mathrm{v}}=\int_{0}^{b}\left(\frac{\eta V_{\mathrm{p}}}{h}\left(\phi_{\mathrm{fg}}+\phi_{\mathrm{fs}}\right)-\phi_{f p} \frac{h}{2} \frac{\mathrm{d} p}{\mathrm{~d} x}\right) \mathrm{d} x
$$

where $\phi_{\mathrm{fs}}$ is shear stress factor, $\phi_{\mathrm{fg}}$ is geometric stress factor, and $\phi_{\mathrm{fb}}$ is pressure stress factor.

The friction force caused by the asperity contact can be computed by the following equation:

$$
F_{\mathrm{a}}=\tau_{0} A_{\mathrm{c}}+\alpha_{0} W_{\mathrm{a}}
$$

where $\tau_{0}$ is a constant of shear tress, and $\alpha_{0}$ is a boundary friction coefficient (here $\alpha_{0}=0.08$ ). $A_{\mathrm{c}}$ is the actual contact area and is given by [12]

$$
A_{\mathrm{c}}=\pi^{2}(\eta \beta \sigma)^{2} A F_{2}\left(\frac{h}{\sigma}\right)
$$

The total friction force is as follows:

$$
F_{\mathrm{t}}=F_{\mathrm{v}}+F_{\mathrm{a}}
$$

All calculated forces above are per unit of (circumferential) length according to the line contact assumption for piston ring simulation. 
Once the shape of the piston ring face is given, the pressure distribution can be calculated by solving Eqs. (3-7). Once the pressure distribution $P$ is obtained, the friction force on the piston ring face can be determined by solving Eqs. (8-11).

It should be noted that the surface of cylinder liners used in practice generally does not comply with a Gaussian distribution of asperities. This is because the liner or bore is crosshatched and honed, which makes a plateau. It is only approximate to assume a Gaussian distribution in our study. The roughness amplitudes are assumed to follow Gaussian distributions with a mean of zero.

\subsection{Oil film temperature and lubricant properties}

In this section, the equations adopted from Refs. $[35,36]$ are summarized for assuming the dynamic characteristics of the lubricant. According to Ma [35], the oil temperature along the engine stroke can be approximated as follows:

$$
\begin{aligned}
T(x)= & T_{\mathrm{TDC}}+\left(4 T_{\mathrm{MID}}-3 T_{\mathrm{TDC}}-T_{\mathrm{BDC}}\right)(x / S) \\
& +2\left(T_{\mathrm{TDC}}+T_{\mathrm{BDC}}-2 T_{\mathrm{MID}}\right)(x / S)^{2}
\end{aligned}
$$

where $T_{\mathrm{TDC}}, T_{\mathrm{MID}}$, and $T_{\mathrm{BDC}}$ are the liner temperatures measured at the top dead center (TDC), the mid-stroke point (MID), and bottom dead center (BDC), respectively [36]. Here, $T_{\mathrm{TDC}}, T_{\mathrm{MID}}$, and $T_{\mathrm{BDC}}$ are 180, 150, and $130{ }^{\circ} \mathrm{C}$, respectively. $S$ is the length of the piston stroke, and $x$ is the piston location downward from the TDC.

Oil viscosity is a function of temperature and can be estimated by Vogel equation as follows:

$$
\eta(T)=\kappa \cdot \exp \left(\frac{\theta_{1}}{\theta_{2}+T}\right)
$$

where, $\kappa, \theta_{1}$, and $\theta_{2}$ are Vogel correlation parameters (see Table A1 in Appendix).

\subsection{Modeling profile of a piston ring face}

Using an inverse method, a ring shape can be expressed as

$$
H(X)=\frac{h(X)}{h_{\mathrm{s}}}
$$

where

$$
\begin{aligned}
& H(1)=H_{0}=\frac{h_{0}}{h_{\mathrm{s}}}, \text { at } X=1 ; \\
& H(0)=H_{0}+1, \text { at } X=0 .
\end{aligned}
$$

According to Refs. $[9,30-32,37]$, to obtain the optimum shape of a piston ring face, the dimensionless film thickness distribution $H(X)$ can be represented in the form of a polynomial of degree $n+1$ with inlet and outlet conditions being satisfied as follows:

$$
H(X)=(X-1) \sum_{j=1}^{n} C_{j} X^{j}-X+\left(H_{0}+1\right)
$$

where $C_{j}(j=1,2, \ldots, n)$ and $H_{0}$ are design variables and can be calculated using the SQP method, until a desired shape of the piston ring face is obtained. The degree $n$ is a positive integer. In Eqs. (5) and (11), $F_{\text {oil }}$ and $F_{\mathrm{t}}$ are functions of the design variables $C_{j}$ and $H_{0}$.

The objective of using the inverse method is to determine the optimum film shape, $H(X)$, to satisfy the balance Eq. (7). Aiming to minimize the friction, the optimization problem entails obtaining the optimum values for $C_{j}$ and $H_{0}$, subject to pressure, shape, and load constraints. Therefore, the optimization problem of the piston ring shape can be described as:

$$
\min _{C_{1}, C_{2}, \ldots, C_{n}, H_{0}} F_{\mathrm{t}}=F_{\mathrm{v}}+F_{\mathrm{a}}
$$

subject to

$$
\begin{gathered}
P_{i} \geq 0, \quad H_{i} \geq 0, \quad i=1,2, \ldots, m \\
F_{\mathrm{g}}+F_{\mathrm{e}}=F_{\text {oil }}+W_{\mathrm{a}}
\end{gathered}
$$

where $P_{i}$ and $H_{i}$ are respectively the fluid pressure and oil film thickness at every node of the piston ring profile, and $m$ is equal to 50 .

\section{Simulation algorithm}

The simulation algorithm was established by considering variable piston velocity, gas pressure, and mixed lubrication conditions, as well as variable lubricant viscosity. Detailed calculation steps are summarized as follows:

Step 1: Calculate the curves of $P_{1}, P_{2}, V_{\mathrm{p}}$ and $\eta$ as functions of $\theta$. 
Step 2: Select three typical working conditions, i.e., TDC neighborhood, midstroke, and BDC neighborhood. Each working condition has different values of $P_{1}, P_{2}$, $V_{\mathrm{p}}, \eta$.

Step 3: Give the value of $n$ and $m$.

Step 4: Use the SQP algorithm to obtain the optimum value of $C_{j}$ and $H_{0}$ for the three typical working conditions, such that three different optimum shapes can be obtained. Figure 2 shows the optimization procedures.

Step 5: Calculate the pressure distribution and friction in all working conditions for the three shapes using the developed FORTRAN-based program.

Step 6: Compare the average friction of the three profiles, and choose the minimum value.

Step 7: The optimum shape that produces the minimum friction is obtained.

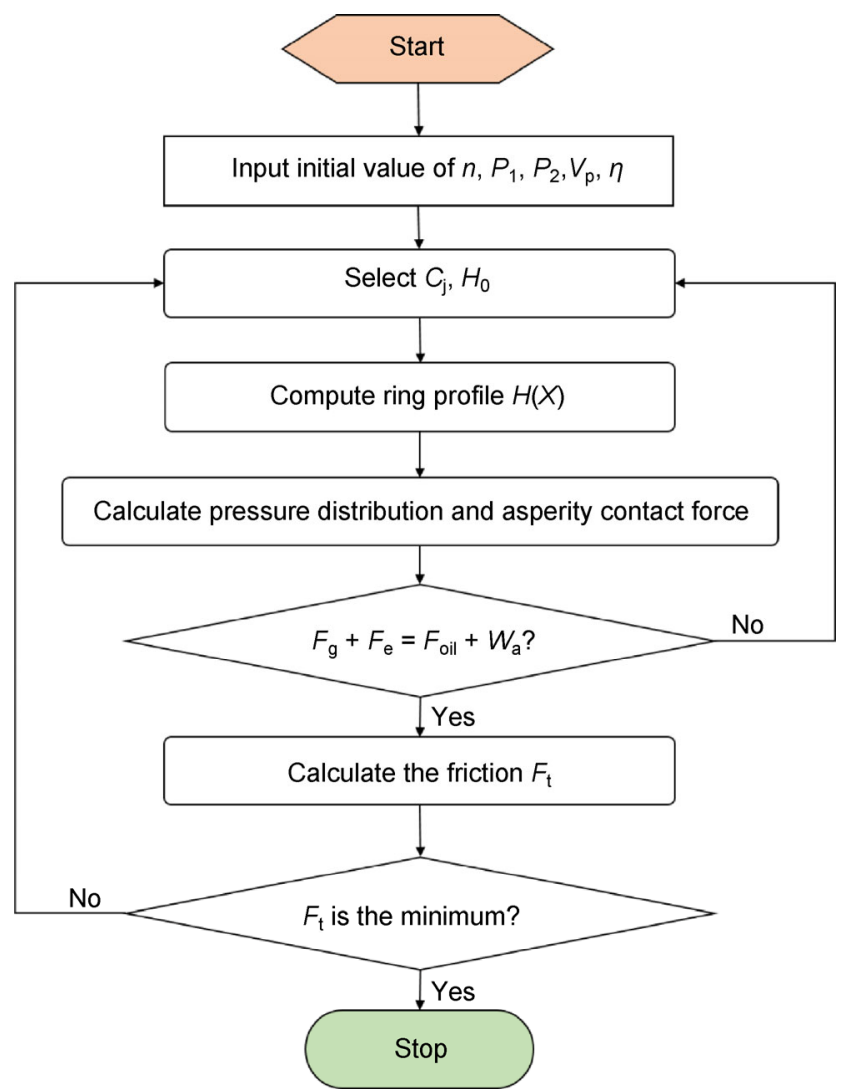

Fig. 2 The flow diagram of the optimization procedure.

\section{Results and discussion}

The second piston ring of a piston was selected for the simulation verification. Table 1 shows the engine parameters and their values for this simulation.
Table 1 Engine conditions.

\begin{tabular}{ccc}
\hline Notation & Units & Value \\
\hline Crank speed & $\mathrm{rpm}$ & 2000 \\
Connecting rod length & $\mathrm{mm}$ & 145.9 \\
Crank radius & $\mathrm{mm}$ & 45.0 \\
Width of the 2nd ring & $\mathrm{mm}$ & 1.5 \\
Roughness of ring & $\mu \mathrm{m}$ & 0.615 \\
Roughness of liner & $\mu \mathrm{m}$ & 0.815 \\
$T_{\mathrm{TDC}}, T_{\mathrm{MID}}, T_{\mathrm{BDC}}$ & ${ }^{\circ} \mathrm{C}$ & Measured \\
Cylinder land & $\mathrm{mpa}$ & Measured \\
\hline
\end{tabular}

Figure 3(a) depicts the ring pressure at a crank speed of 2,000 r/min. The cylinder pressure was measured. There are typically three rings on a piston. They are the top ring, second ring, and oil ring. "Second land" refers to the air chamber between the top ring and the second ring. "Third land" refers to the air chamber
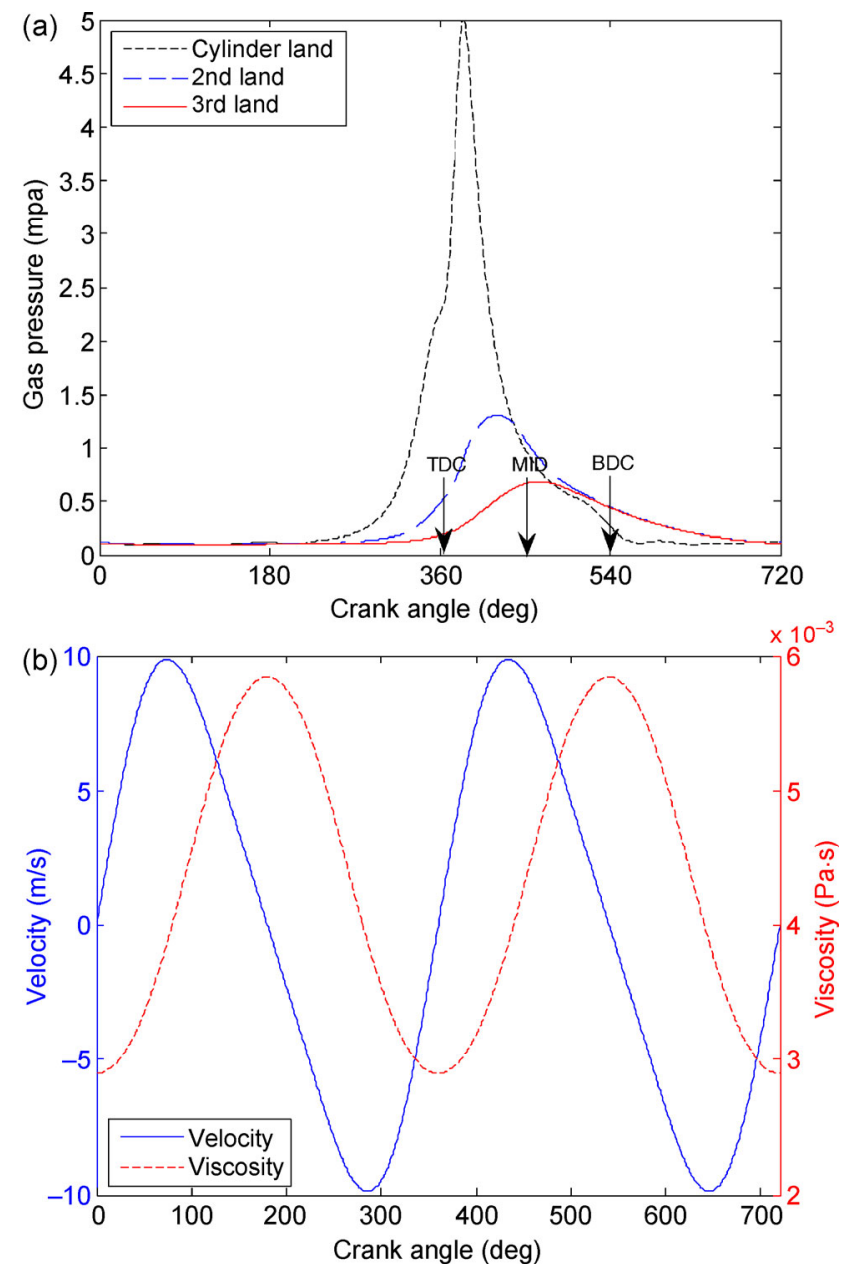

Fig. 3 Working conditions: (a) ring-pressures and (b) velocity and viscosity. 
between the second ring and the oil ring. The pressures in the second and third lands were calculated [38]. As mentioned in section 1, the optimum piston ring profile should be the profile giving the minimum friction in a complete engine cycle and not just at the maximum piston speed. Figure $3(\mathrm{~b})$ presents the variation in piston velocity and lubricant viscosity in an engine cycle, calculated from Eqs. (2), (12), and (13). As shown in Fig. 3(b), owing to the variation in temperature along the cylinder liner, the lubricant viscosity rises as the piston moves to the $\mathrm{BDC}$, both in the intake stroke $\left(0^{\circ}-180^{\circ}\right)$, and the expansion stroke $\left(360^{\circ}-540^{\circ}\right)$. In the other two strokes, the oil viscosity declines as the piston moves to the TDC.

\subsection{The results of SQP algorithm}

After selecting one typical working condition, the optimum profile considering mixed lubrication was obtained using the SQP algorithm, as shown in Fig. 2. This study selected three typical working conditions, i.e., TDC, MID, and BDC for each value of $n$. The value of $n$ varied from 1 to 7 . Hence, there were 21 different profiles.

Figure 4(a) describes the optimal profile of the piston ring using the SQP algorithm for the three working conditions (TDC, MID, and BDC) and shows
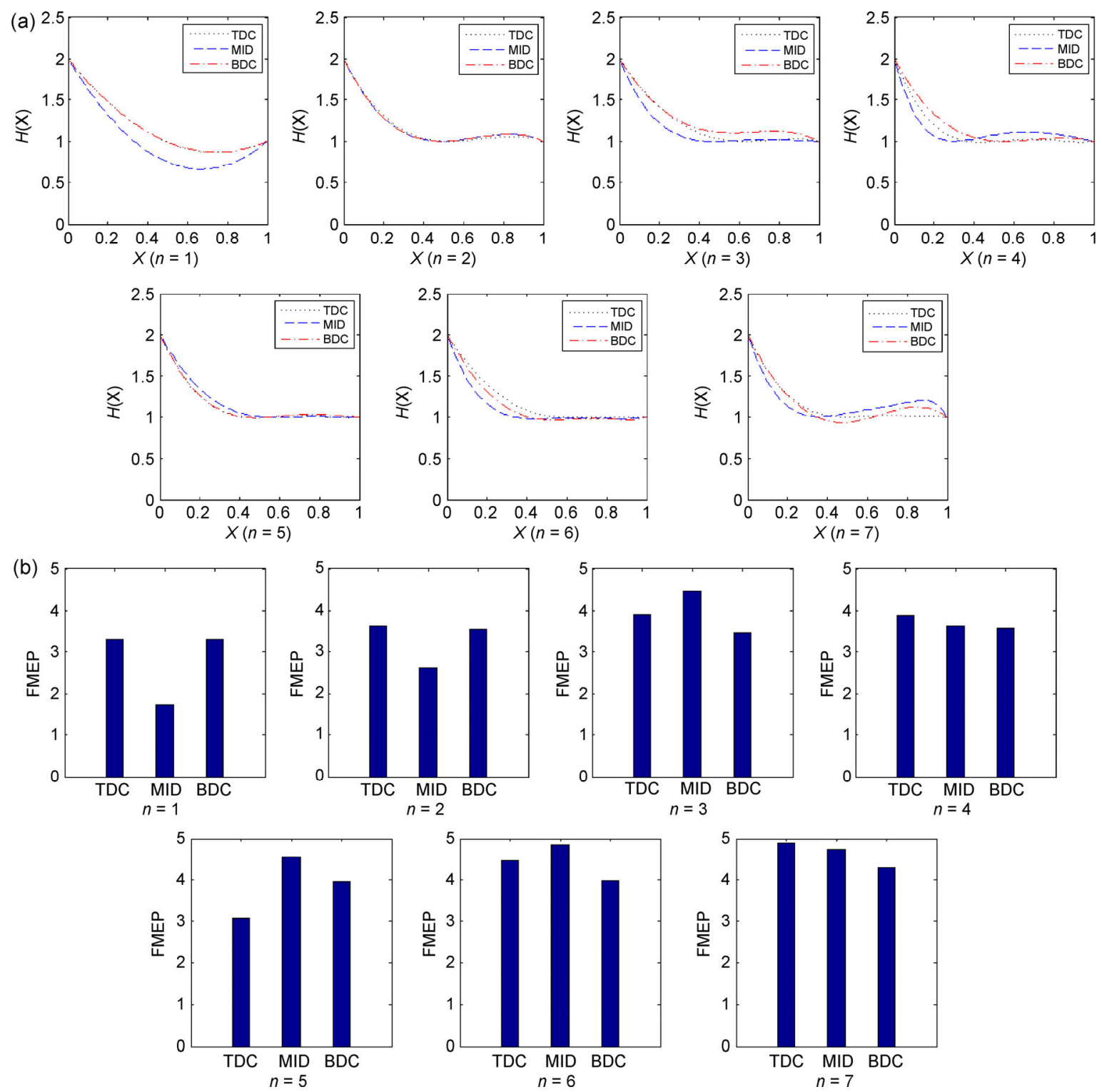

Fig. 4 The results of SQP algorithm: (a) the optimum profiles and (b) the FMEPs of different profiles. 
the effect of the parameter $n$ on the optimum shape with the assumption that all the other parameters are kept constant. $X=0$ and $X=1$ represent the top and bottom of the ring, respectively. As shown in Fig. 4(a), different working conditions resulted in different optimum shapes. Selecting the best shape depends on the mean effective pressure (FMEP) for contact friction in the whole cycle, as shown in Fig. 4(b). In this study, FMEP refers to the friction work normalized by engine displacement [34]. It can be seen from Fig. 4(b) that the best shapes are the optimum profiles in the MID working condition when the design parameter $n$ is 1 or 2 , while the best shapes are the optimum profiles in the TDC or BDC working condition for the other values of $n$. A slight change in the piston ring profile will induce a significant change in FMEP. In Fig. 4(b), for the " $n=1$ " condition, the maximum reduction in FMEP reaches $47.88 \%$.

After comparing the FMEPs of three different optimum shapes calculated from three different working conditions, this study selected the best shapes that produced the least amount of FMEP for each value of $n$. The selected best profiles are shown in Fig. 5. The selected best profiles in Fig. 5 are from the optimum profiles in Fig. 4(a). They were chosen based on FMEP for a complete operation cycle, as shown in Fig. 4(b). The best profiles for different positions vary. Generally, it is more beneficial to select the best profile for the whole operation. However, owing to the limitations of this research, only the best profile for a particular condition could be selected. Then, three typical working

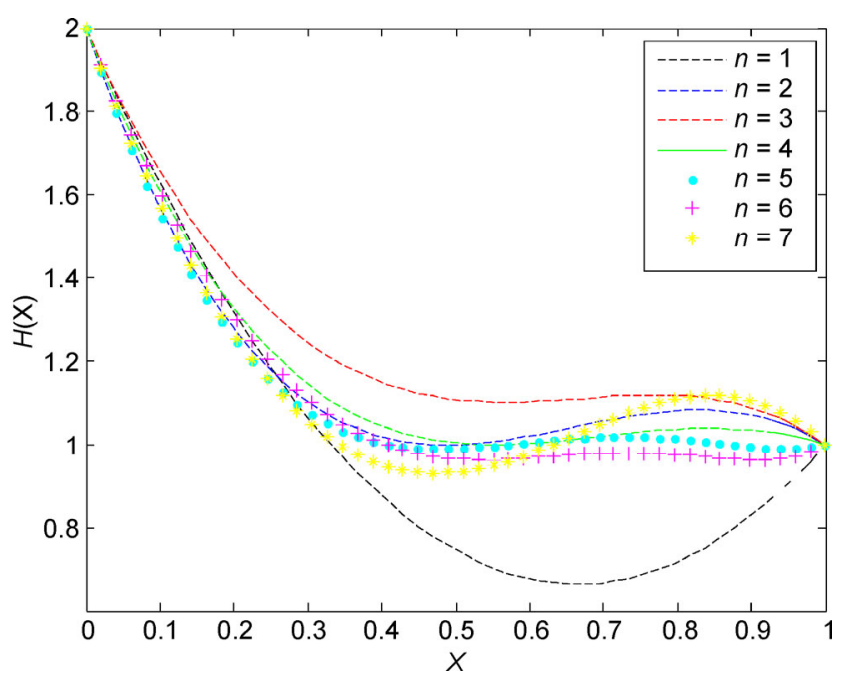

Fig. 5 The selected best profiles. conditions (TDC, MID, and BDC) were selected for the design of the optimum shape of a piston ring, and the FMEPs that the optimum shapes generated in the whole operation for the best profile were compared.

\subsection{Effect of design parameter $n$ on oil film pressure}

In a piston ring-liner system, the worst working condition is TDC, where the crank angle is $360^{\circ}$, for its high temperature and pressure environment. Hence, this study chose the worst working condition and analyzed the effects of the degree of polynomial $(n)$ on the TDC working condition. Figure 6(a) illustrates the variation of the pressure distribution, and Fig. 6(b) depicts the variation of the oil film load-carrying capacity in different shapes. The degree of the polynomial function employed to describe the shape of piston ring faces had a significant influence on the pressure distribution and oil film load-carrying capacity. When the design parameter, $n \in[2,6]$, the load-carrying capacity of the oil film was improved.
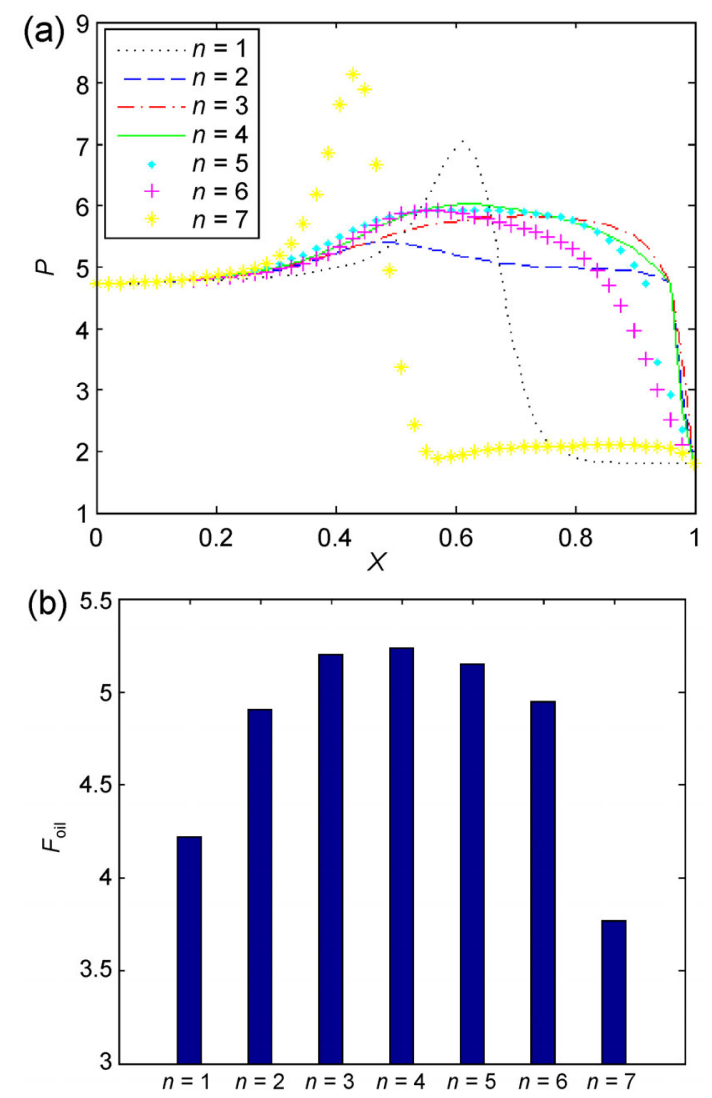

Fig. 6 The effect of $n$ on oil film pressure: (a) pressure distribution and (b) load-carrying capacity. 
As for $n=1$ or 7 , there was a sharp pressure peak and lower oil film load-carrying capacity. This was because of the high arched profile and the position of the arch. This indicates that the high arched profile should be avoided, and the position of the arch should be chosen properly.

\subsection{Effect of design parameter $n$ on friction}

Figure 7 presents the effect of the degree of the polynomial function on the friction mean effective pressure (FMEP) in a complete engine cycle. Here, $F_{\mathrm{a}}$ is the asperity contact friction mean effective pressure, $F_{\mathrm{v}}$ is the viscous friction mean effective pressure, and $F_{\mathrm{t}}$ is the sum of $F_{\mathrm{a}}$ and $F_{\mathrm{v}}$. As can be seen in Fig. 7, the greater the value of $n$, i.e., the degree of the polynomial function used for the piston ring profile, as described in Eq. (14), the higher FMEP is, except for $n=5$. When $n \in[1,5]$, a lower FMEP can be achieved. In addition, $F_{\mathrm{a}}$ accounts for about $80 \%$ of $F_{\mathrm{t}}$. It can be concluded that mixed lubrication cannot be ignored in a piston ring profile design.

\subsection{Effect of design parameter $n$ on minimum oil film thickness}

Figure 8 presents the influence of the design parameter, $n$, on the minimum oil film thickness. It is similar to Fig. 6(b) because the minimum oil film thickness always occurs at the TDC position when the crank angle is $360^{\circ}$. With the increase of the thickness of the oil film, the load-carrying capacity of the oil film also increased. The total oil film thickness was

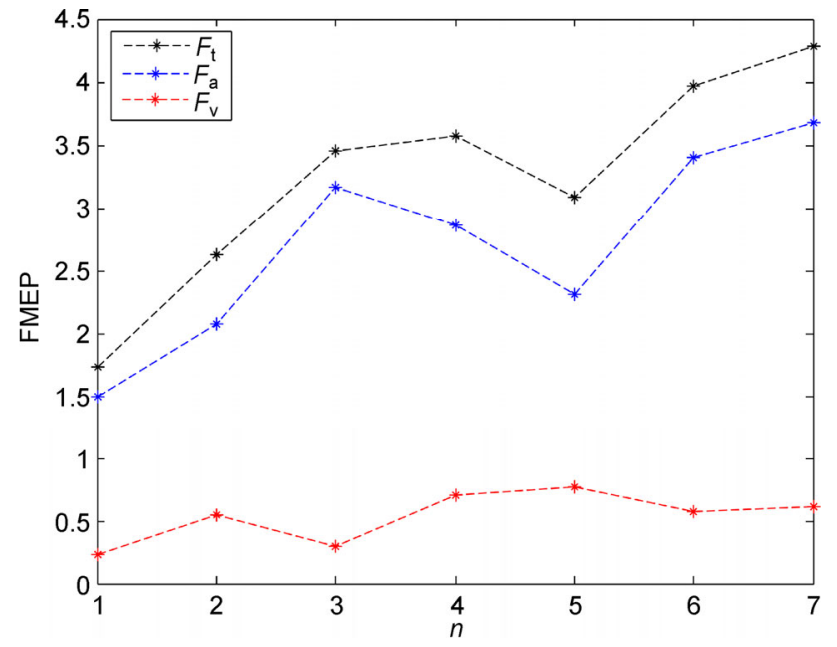

Fig. 7 The effect of $n$ on friction.

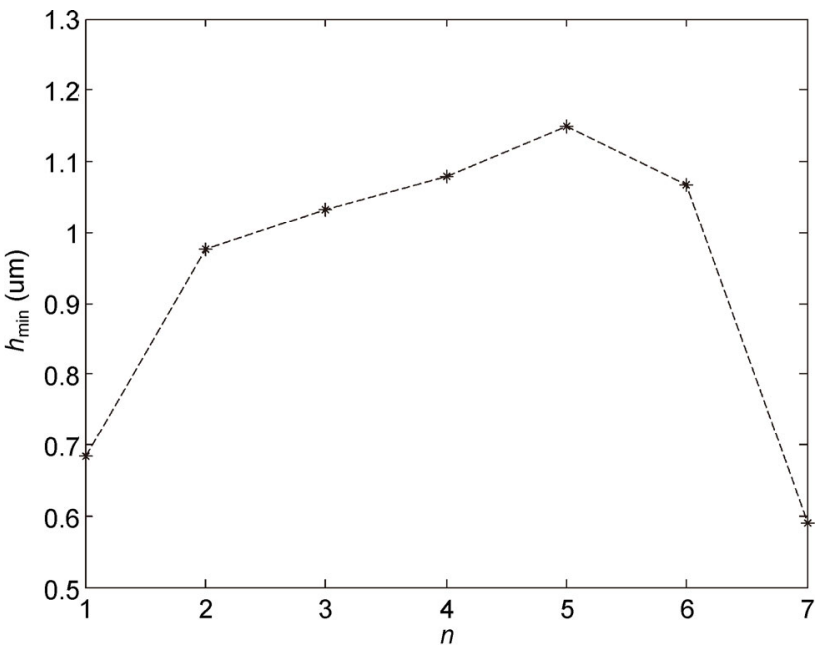

Fig. 8 The effect of $n$ on minimum oil film thickness.

determined by the minimum oil film thickness and the profile. When $h<4 \sigma$, there is asperity contact. Hence, a decrease in minimum oil film thickness results in an increase in the area of asperity contact. Therefore the results of $n \in[2,6]$ are better for generating a minimum oil film thickness.

\section{Conclusions and future work}

The present study proposed a design approach for optimizing the piston ring profiles by considering mixed lubrication, the variation of piston speed and gas pressure, as well as the change of lubricant viscosity with temperature along the engine stroke. The piston ring profile was modeled using an inverse method, and the optimization was performed using the sequential quadratic programming algorithm. Based on the proposed approach, effects of the different profiles of a piston ring face with different values of the design parameter $n$ on friction, pressure distribution, oil film load-carrying capacity, and minimum oil film thickness were investigated, considering hydrodynamic lubrication and mixed lubrication regimes. The results showed that, as the degree of the polynomial function increased (i.e., $n$ increased), the load-carrying capacity and minimum thickness of the oil film increased, followed by a decrease. When $n \in\{3,4,5\}$, the loadcarrying capacity of the oil film was better. Additionally, FMEP increased with the magnitude of the design parameter $n$. The profiles corresponding to $n \in\{1,2,5\}$ were more appropriate for reducing FMEP. For the 
oil film thickness, the best profiles corresponded to $n \in\{4,5,6\}$. To balance the oil film load-carrying capacity and FMEP, an appropriate $n$ should be selected. When $n=5$, the minimization of friction and maximization of the oil film load-carrying capacity can be achieved simultaneously.

Future works will be carried out as follows: first, an optimum profile for the complete engine cycle will be selected, not just for a particular working condition; second, the 1D model of Reynolds equation will be expanded to a $2 \mathrm{D}$ model to simulate real contact; finally, a more accurate roughness model will be determined for representing ring and liner surfaces rather than assuming that the asperities follow Gaussian distribution.

\section{Acknowledgments}

This study is supported by the National Natural Science Foundation of China (Nos. 51575340 and 51575342), Research Project of State Key Laboratory of Mechanical System and Vibration (No. MSVZD201104).

\section{Appendix}

Table A1 Input parameter of Vogel equation [36].

\begin{tabular}{ccccccc}
\hline $\begin{array}{c}\text { SAE } \\
\text { viscosity } \\
\text { grade }\end{array}$ & $\begin{array}{c}\kappa \\
(\mathrm{mPa} \cdot \mathrm{s})\end{array}$ & $\begin{array}{c}\theta_{1} \\
\left({ }^{\circ} \mathrm{C}\right)\end{array}$ & $\begin{array}{c}\theta_{2} \\
\left({ }^{\circ} \mathrm{C}\right)\end{array}$ & $m_{1}$ & $A$ & $\begin{array}{c}B \\
\left({ }^{\circ} \mathrm{C}^{-1}\right)\end{array}$ \\
\hline $15 \mathrm{~W} 40$ & 0.108 & 933.5 & 103.9 & 0.80 & 2.5 & 0.0225 \\
\hline
\end{tabular}

Open Access: The articles published in this journal are distributed under the terms of the Creative Commons Attribution 4.0 International License (http:// creativecommons.org/licenses/by/4.0/), which permits unrestricted use, distribution, and reproduction in any medium, provided you give appropriate credit to the original author(s) and the source, provide a link to the Creative Commons license, and indicate if changes were made.

\section{Reference}

[1] Wong $\mathrm{V} \mathrm{W}$, Tung S. Overview of automotive engine friction and reduction trends-Effects of surface, material and lubricant-additive technologies. Friction 4(1): 1-28 (2016)
[2] Holmberg K, Andersson P, Erdemir A. Global energy consumption due to friction in passenger cars. Tribol Int 47 : 221-234 (2012)

[3] Ting L L. A review of present information on piston ring tribology. SAE Paper 852355, 1985.

[4] Furuhama S. A dynamic theory of piston ring lubrication. JSME 2(7): 423-428 (1959)

[5] Dowson D, Ruddy B L, Economou P N. The elastohydrodynamic lubrication of piston rings. Proc $R$ Soc 386: 409-430 (1983)

[6] Hu Y, Cheng H S, Arai T, Kobayashi Y, Aoyama S. Numerical simulation of piston ring in mixed lubrication-A non-axi-symmetrical analysis. ASME J Tribol 116: 470-478 (1994).

[7] Tian T. Modeling the performance of the piston ring-pack in internal combustion engines. $\mathrm{PhD}$ thesis, Massachusetts Institute of Technology, Cambridge, Massachusetts, USA, 1997.

[8] Akalin O, Newaz G M. Piston ring cylinder bore friction modeling in mixed lubrication regime: Part 1-Analytical results. ASME J Tribol 23: 211-223 (2001)

[9] Chu L M, Chang Y P, Yang J H. Profile design of piston ring using inverse method. J Mar Sci Technol 16(1): 64-70 (2008)

[10] Meng F M, Wang J X, Xiao K. A study of the influences of particles in the gas flow passage of a piston ring pack on the tribological performances of the piston ring. Proc IMechE, Part C: J Mech Eng Sci 224(1): 201-215 (2010)

[11] Patir N, Cheng H S. An average flow model for determining effects of three-dimensional roughness on partial hydrodynamic lubrication. ASME J Lubr Technol 100: 12-17 (1978)

[12] Greenwood J A, Tripp J H. The contact of two nominally flat rough surfaces. Proc Inst Mech Eng 185: 625-633 (1971)

[13] Akalin O, Newaz G M. Piston ring-cylinder bore friction modeling in mixed lubrication regime: Part II-Correlation with bench test data. ASME J Tribol 123(1): 219-223 (2001)

[14] Styles G, Rahmani R, Rahnejat H, Fitzsimons B. In-cycle and life-time friction transience in piston ring-liner conjunction under mixed regime of lubrication. Int J Eng Res 15(7): 862-876 (2014)

[15] Guo Y B, Lu X Q, Li W Y, He T, Zou D Q. A mixed-lubrication model considering elastoplastic contact for a piston ring and application to a ring pack. Proc IMechE, Part D: J Aut Eng 229(2): 174-188 (2015)

[16] Tung S C, Gao H. Tribological characteristics and surface interaction between piston ring coatings and a blend of energy-conserving oils and ethanol fuels. Wear 255(7-12): 1276-1285 (2003)

[17] Kano M. Overview of DLC-coated engine components. In Cha S C, Erdemir A Eds. Coating Technology for Vehicle 
Applications. Springer International Publishing, Switzerland, 2015.

[18] Skopp A, Kelling N, Woydt M, Berger L M. Thermally sprayed titanium suboxide coatings for piston ring/ cylinder liners under mixed lubrication and dry-running conditions. Wear 262(9-10): 1061-1070 (2007)

[19] Etsion I, Sher E. Improving fuel efficiency with laser surface textured piston rings. Tribol Int 42(4): 542-547 (2009)

[20] Zavos A B, Nikolakopoulos P G. Simulation of piston ring tribology with surface texturing for internal combustion engines. Lubr Sci 27(3): 151-176 (2015)

[21] Tomanik E, Profito F J, Zachariadis D C. Modelling the hydrodynamic support of cylinder bore and piston rings with laser textured surfaces. Tribol Int 59: 90-96 (2013)

[22] Biboulet N, Bouassida H, Lubrecht A. Cross hatched texture influence on the load carrying capacity of oil control rings. Tribol Int 82: 12-19 (2015)

[23] Urabe M, Takakura T, Metoki S, Yanagisawa M, Murata H. Mechanism of and fuel efficiency improvement by dimple texturing on liner surface for reduction of friction between piston rings and cylinder bore. SAE Technical Paper Series, 2014.

[24] Tian T. Dynamic behaviours of piston rings and their practical impact. Part 1: Ring flutter and ring collapse and their effects on gas flow and oil transport. Proc IMechE, Part J: J Eng Tribol 216(4): 209-228 (2002)

[25] Kapsiz M, Durat M. Ficici F. Friction and wear studies between cylinder liner and piston ring pair using Taguchi design method. Adv Eng Softw 42(8): 595-603 (2011)

[26] Smith E H. Optimising the design of a piston-ring pack using DoE methods. Tribol Int 44: 29-41 (2011)

[27] Morris N, Rahmani R, Rahnejat H, King P D, Fitzsimons B. The influence of piston ring geometry and topography on friction. Proc IMechE, Part J: J Eng Tribol 227(2): 141153 (2013)

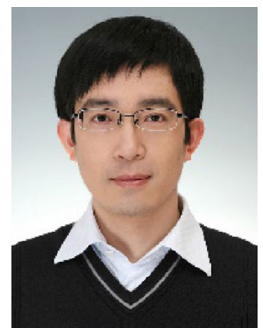

Zhinan ZHANG. He received his Ph.D. degree in 2011 from Shanghai Jiao Tong University, Shanghai, China. After that he was a post doctor in Shanghai Jiao Tong University. He is now working as
[28] Wu B, Zhang Z N, Wang P. Effect of design parameters on the reduction of top piston ring friction. Appl Mech Mater 246-247: 1268-1272 (2012)

[29] Singh R, Chaudhary R, Pandey R, Maji S. Experimental studies for the role of piston rings' face profiles on performance of a diesel engine fueled with diesel and jatropha based biodiesel. J Sci Ind Res 71: 57-62 (2012)

[30] Cheng $\mathrm{C} \mathrm{H}$, Chang M H. Shape design for surface of a slider by inverse method. ASME J Tribol 126(3): 519-526 (2004)

[31] Chu H M. Shape optimum design of a slider bearing using inverse method. Tribol Int 40: 275-279 (2007)

[32] Elsharkawy A A, Alyaqout S F. Optimum shape design for surface of a porous slider bearing lubricated with couple stress fluid. Lubr Sci 21(1): 1-12 (2009)

[33] Meng F M, Wang Q, Hua D, Liu S B. A simple method to calculate contact factor used in average flow model. ASME J Tribol 132(2): 024505 (2010)

[34] Wong V, Tian T, Takata R, Jocsak J. Low-engine-friction technology for advanced natural-gas reciprocating engines. Report, Massachusetts Institute of Technology, Cambridge, Massachusetts, USA, 2006.

[35] Ma M T. Incorporation of lubricant shear-thinning in a two-dimensional lubrication analysis for automotive pistonring packs. SAE Paper No. 2000-01-1786.

[36] Ning L P, Meng X H, Xie Y B. Effects of lubricant shear thinning on the mixed lubrication of piston skirt-liner system. Proc IMechE, Part C: J Mech Eng Sci 227(7): 1585-1598 (2013)

[37] Zhang Z N, Liu J, Tang Y H, Meng X H. Optimizing the shape of top piston ring face using inverse method. Ind Lubr Tribol 68(1): 9-15 (2016)

[38] Ye X M. Numerical investigation and application of threedimensional lubrication performance in piston ring pack. (In Chinese). PhD Thesis, Huazhong University of Science and Technology, China, 2004.

an assistant researcher in the School of Mechanical Engineering, Shanghai Jiao Tong University. His research interests include computational design and analysis of tribosystems, theory and methods of design engineering and innovation. 